\title{
English Goalkeepers are not Responsible for England's Poor Performance in Penalty Shootouts in the Past
}

Michel Brinkschulte ( $\nabla$ m.brinkschulte@dshs-koeln.de)

German Sport University Cologne

Philip Furley

German Sport University Cologne

Daniel Memmert

German Sport University Cologne

\section{Research Article}

Keywords: goalkeeper, football, penalty kick, penalty shootout, nationality

Posted Date: April 14th, 2021

DOl: https://doi.org/10.21203/rs.3.rs-400697/v1

License: (1) This work is licensed under a Creative Commons Attribution 4.0 International License.

Read Full License

Version of Record: A version of this preprint was published at Scientific Reports on December 1st, 2021. See the published version at https://doi.org/10.1038/s41598-021-04118-6. 


\section{Abstract}

Scrutinizing public opinion is one of the central goals of science as the divergence between public opinion and scientific evidence can have negative consequences. The present study aimed to further investigate the alleged English 'penalty curse' and determine if it can be linked to the prevalent stereotype of the 'English goalkeeper problem'. We analyzed a large sample of 2,379 penalty kicks that 629 different goalkeepers faced in World Cups and European Championships, as well as in the Champions and Europa League by comparing the goalkeeper success rates of different nations. However, the results do not reveal meaningful significant differences between these success rates (on average $22.23 \%$ ). Consequently, we conclude that English goalkeepers are not responsible for England's poor performance in penalties in the past as they perform as well as goalkeepers from other nations and, in turn, provide a counterargument to the widespread stereotype that 'England has a goalkeeper problem'.

\section{Introduction}

Public opinion and scientific evidence unfortunately do not always overlap and can sometimes substantially diverge. For example, there is high consensus in science that human activities cause global warming, whereas there is little consensus on this in the public opinion [1]. This divergence between public opinion and scientific evidence can have negative consequences. In the case of global warming, it seems obvious that it is problematic if large proportions of the public do not believe that their own behavior and activities contribute to global warming. There are many more examples of problems that can occur if public opinion diverges from scientific knowledge. For example, if large proportions of people have certain stereotypes concerning different national or ethnic groups, this can lead to discrimination or stereotype threat (i.e., people behave/perform in accordance with the stereotype [2]). For this reason, it is important to conduct rigorous scientific tests to find out if public opinion stands the test of the scientific method.

Given the immense public interest in professional sports, it is not surprising that there are many public opinions and stereotyping in sports (e. g., [3]). For example, a recent study [4] did not find evidence for the wildly held stereotype that English soccer players are bad at kicking penalties. Nor did this research find evidence for other commonly held stereotypes, for instance, that players of some nations like Germany perform extraordinarily well in penalty kicks. Pertinent to the present research, there is another commonly held stereotype concerning English and German soccer players, and that is that English goalkeepers are 'no good at goalkeeping' while German goalkeepers are exceptionally good. Not only does the media (e. g., $[5,6])$ support this stereotype, but also the International Federation of Football History \& Statistics (IFFHS) and UEFA who give out the most prestigious goalkeeper awards (mainly based on the subjective perception of their judges). German keepers are leading the current list of winners (up until 2020) for all three of these awards (IFFHS World's Best Goalkeeper: 9, UEFA Best European Goalkeeper: 13, UEFA Best Club Goalkeeper: 6). On the other hand, the English press is particularly critical of their goalies, keeping up the alleged 'English Goalkeeper Problem' for years (e.g., [7-10]). None of the three goalkeeper awards were ever received by an English goalie, a fact that might even negatively influence the public opinion about 
this stereotype in an additional way. Scientific evidence supporting this public opinion does not exist. If these stereotypes are actually true, it should therefore be evident in sports performance data. While the performance of a goalkeeper as a whole cannot be easily operationalized, we decided to compare goalkeeping performance as a function of keeper nationality in the standardized penalty kick situation. The performance in penalty kicks is an essential aspect for goalkeeping as penalties have always played an important role in major tournaments and will likely keep playing a crucial role in upcoming events like the UEFA European Championship 2021.

Looking at the task at hand, scoring a penalty kick seems to be quite easy, especially for a professional football player: The shot is taken from a spot that is only twelve yards away from the goal. No one is allowed to interfere in the process until the player's foot touches the ball. The only obstacle is the opposing goalkeeper for whom it is extremely difficult to successfully guard the net if the penalty is kicked with enough force in the right direction. Still, at the highest international level (World Cups and European Championships as well as Champions and Europa League), about 25 percent of all penalty kicks are either saved by the goalkeeper or miss the goal entirely. If there is some truth behind the stereotype that England has relatively bad goalies, it seems feasible that they would save less penalties than keepers from different nations. A brief look at the numbers of the penalty shootouts involving the England national team does in fact show a negative balance. Since the penalty shootout was introduced to major international tournaments in 1976, the Three Lions have only won three (World Cup in 2018; European Championship in 1996; Nations League in 2019) out of the nine shootouts they participated in (losses: World Cups in 1990, 1998 and 2006; European Championships in 1996, 2004, and 2012). Hence, it might not be that the penalty kickers of England were responsible for this subpar performance [4], but the English goalies instead. For this reason, this study aims to determine whether the success ratios of goalkeepers in regard to their nationality differ from each other or from the overall average.

Our reasoning for the importance of this research follows that of Brinkschulte, Furley, and Memmert [4], by pointing out that there is evidence showing the impact of stereotypes on performance in sports, even if those stereotypes are not actually true. A phenomenon that can be considered as being of particular relevance in this regard is the so-called stereotype threat [2]. Research about this phenomenon indicates that solely introducing a negative stereotype about a social group can perhaps lead to a decrease in performance of members of that group. In the domain of sports, various studies were able to show that stereotypes can negatively influence athletic performance [11, 12]. An alleged stereotype could, for example, not only have an inhibiting effect on learning a new motor skill [13], but it could also lead to an athlete simply not trying their best [14]. For this reason, we see it as theoretically possible that the continued existence of the stereotype of the 'English goalkeeper problem' could potentially have concerning consequences: First of all, the mere knowledge about this stereotype might contribute to English keepers actually underperforming (when facing penalties or during matches in general) in the sense of a self-fulfilling prophecy. Secondly, when considering the bigger picture, the belief might even lead to clubs deciding against signing an English goalie or, what might be the worst, young children may not be motivated to go in goal due to negative stereotypes associated with English goalkeeping. 
In conclusion, we believe that it is important to examine if English goalkeepers per se perform poorly when facing penalty kicks. If they do indeed perform poorly, a subpar performance of English goalies should be apparent when comparing their success rates with the ones of keepers from other countries. Opposing results would suggest that English goalies are not responsible for England's poor performance in important penalty shootouts in the past and, in addition, provide a counterargument to the prevalent stereotype of 'England having a goalkeeper problem' as stated in the media. To find out, we evaluated the success rates of goalkeepers in penalty kicks they faced in European Championships and World Cups as well as on the highest club level in the UEFA Champions League and in the UEFA Europa League.

\section{Methods}

Our methodological approach followed that of Brinkschulte et al. [4]. First, we sampled all penalty kicks taken in penalty shootouts and during the matches in European and World Cup matches since 1976. Second, we sampled all penalty kicks taken in shootouts and during the matches in the UEFA Champions League since the 2000/01 season (there are no reliable data available for penalty kicks taken before the 2000/01 season) and in the UEFA Europa League since the 2004/05 season (the group stage was introduced in the 2004/05 season). We collected the data from various websites that provide information on the different competitions, goalkeeper profiles, penalty shootouts, and in-game penalty kicks (e.g., soccerstats.com, wikipedia.org, worldfootball.net, fifa.com, uefa.com, transfermarkt.de). Along with listing the goalkeepers' names and the dates of the seasons, we coded each penalty kick as either saved or scored. The coded penalties were double-checked using multiple sources. We then used this information to calculate a success rate for each individual keeper. Additionally, we coded the nationality of all goalies. The independent variable was the nationality of the goalkeeper. The dependent variable was the success rate (percentage of saved penalty kicks plus the additional penalties that hit the post/crossbar or missed the goal) of the respective goalkeeper. As, theoretically, no professional football player would hit the goal post/crossbar or miss the goal entirely when taking an important penalty kick without a goalkeeper guarding the net, these events were considered goalkeeper success as well. Nevertheless, we report inferential statistics for both success rates (i.e., percentages of saved plus missed penalties) and percentages of saved penalties (i.e., excluding penalties that hit the post/crossbar or missed the goal). In all tournaments, we distinguished between performance in penalty shootouts and performance in in-game penalties. We used the same nations as previous research on cross-national penalty analyses [4]. In the analysis, we directly compared the success rates of goalkeepers from England, Germany, Spain, Italy, Netherlands, Brazil, Argentina, and France as they can be considered some of the biggest football nations and, in addition, are amongst the countries with the highest number of goalies in the analyzed competitions. The success rates of keepers from all remaining nations were taken together and consolidated into 'other'.

Data were analyzed with univariate ANOVAs and Bonferroni corrected pairwise comparisons. The level of significance was set at 0.05 . Partial eta-squared effect sizes were calculated and interpreted in line with statistical convention as 0.01 being a small effect, 0.06 a medium effect, and 0.14 a large effect. In addition, we calculated one-sample t-tests comparing the performance of every nation to the mean of the 
entire sample. If assumptions of the parametric tests were violated, we conducted non-parametric tests (i.e., Mann-Whitney-U-Tests).

\section{Results}

\section{World Cups and European Championships.}

Penalty shootouts. Within penalty shootouts, 71 different goalkeepers faced 473 penalties. On average, the goalkeeper success rate was 26.29 percent $(S D=21.51 ; 13.55$ for percent saved; $S D=15.90)$. A univariate ANOVA revealed neither a main effect for the factor nationality on the goalkeeper success rates $\left(F[8,62]=0.752, p=.646, \eta^{2}=0.088\right)$ nor on the percentages saved $\left(F[8,62]=1.369, p=.228, \eta^{2}=\right.$ $0.150)$. Although the effect was non-significant, it can be considered a medium effect for the total success rate and a large effect for the percentage of saved penalties by statistical convention. None of the Bonferroni corrected pairwise comparisons revealed significant differences between any of the analyzed nations (all $p>$.99). Hence, there were no significant differences between the success rates or percentages saved of goalkeepers from different nations. A Kruskal-Wallis test for the nine different nation categories confirmed this non-significant effect on goalkeeper success rates $(\chi 2=7.764, \mathrm{df}=8, p$ $=.457$ ) and on percentages saved $(\mathrm{X} 2=10.476, \mathrm{df}=8, p=.233$ ). None of the nations significantly (all $p>$ .179 , two-tailed) differed from the overall sample mean success rate of 26.29 percent nor from the overall sample mean of 13.55 percent saved penalties (all $p>.166$; except for the Netherlands who saved significantly less penalties: $1.67 \%, S D=2.88, p=.019$ ).

In-game penalties. Within in-game penalties, 142 different goalkeepers faced 237 penalties. On average, the goalkeeper success rate was 19.18 percent $(S D=33.40 ; 8.41$ for percent saved; $S D=23.16)$. A univariate ANOVA revealed neither a main effect for the factor nationality on the goalkeeper success rates $\left(F[8,133]=0.376, p=.932, \eta^{2}=0.022\right)$ nor on the percentages saved $\left(F[8,133]=0.222, p=.987, \eta^{2}=\right.$ 0.013). Although the effect was non-significant, it can be considered a small effect for both the total success rate and the percentage of saved penalties by statistical convention. None of the Bonferroni corrected pairwise comparisons revealed significant differences between any of the analyzed nations (all $p>$.99). Hence, there were no significant differences between the success rates of goalkeepers from different nations. A Kruskal-Wallis test for the nine different nation categories confirmed this nonsignificant effect on goalkeeper success rates $(\chi 2=4.668, \mathrm{df}=8, p=.792)$ and on percentages saved $(\mathrm{X} 2$ $=4.166, \mathrm{df}=8, p=.842$ ). None of the nations significantly (all $p>.469$, two-tailed) differed from the overall sample mean success rate of 19.18 percent nor from the overall sample mean of 8.41 percent saved penalties (all $p>$.544). The goalkeeper performance (success rate) in World Cups and European Championships as a function of nationality and type of penalty kick (shootout vs. in-game) is shown in Figure 1.

\section{Champions League and Europa League.}

Penalty shootouts. Within penalty shootouts, 48 different goalkeepers faced 311 penalties. On average, the goalkeeper success rate was 27.95 percent $(S D=19.58 ; 20.35$ for percent saved; $S D=18.23)$. A 
univariate ANOVA revealed neither a main effect for the factor nationality on the goalkeeper success rates $\left(F[7,40]=0.944, p=.484, \eta^{2}=0.142\right)$ nor on the percentages saved $\left(F[7,40]=0.734, p=.644, \eta^{2}=\right.$ 0.114). Although the effect was non-significant, it can be considered a large effect for the total success rate and a medium effect for the percentage of saved penalties by statistical convention. None of the Bonferroni corrected pairwise comparisons revealed significant differences between any of the analyzed nations (all $p>$.99). Hence, there were no significant differences between the success rates of goalkeepers from different nations. A Kruskal-Wallis test for the nine different nation categories confirmed this non-significant effect on goalkeeper success rates $(\chi 2=7.124, \mathrm{df}=7, p=.416)$ and on percentages saved $(\chi 2=6.079, \mathrm{df}=7, p=.531)$. None of the nations significantly (all $p>.085$, two-tailed) differed from the overall sample mean success rate of 27.95 percent nor from the overall sample mean of 20.35 percent saved penalties (all $p>.192$; except for the Netherlands who saved significantly less penalties: $6.75 \%, S D=7.81, p=.040$ ).

In-game penalties. Within in-game penalties, 512 different goalkeepers faced 1,358 penalties. On average, the goalkeeper success rate was 23.47 percent $(S D=32.02 ; 18.76$ for percent saved penalties; $S D=$ 29.89). A univariate ANOVA revealed neither a main effect for the factor nationality on the goalkeeper success rates $\left(F[8,503]=0.372, p=.935, \eta^{2}=0.006\right)$ nor on the percentages saved $(F[8,503]=0.945, p=$ $\left..479, \eta^{2}=0.015\right)$. Although the effect was non-significant, it can be considered a small effect for the percentage of saved penalties by statistical convention. None of the Bonferroni corrected pairwise comparisons revealed significant differences between any of the analyzed nations (all $p>.99$ ). Hence, there were no significant differences between the success rates of goalkeepers from different nations. A Kruskal-Wallis test for the nine different nation categories confirmed this non-significant effect on goalkeeper success rates $(\chi 2=3.459, \mathrm{df}=8, p=.902)$ and on percentages saved $(\chi 2=7.847, \mathrm{df}=8, p=$ .449). None of the nations significantly (all $p>.223$, two-tailed) differed from the overall sample mean success rate of 23.47 percent nor from the overall sample mean of 18.76 percent saved penalties (all $p>$ .222; except for the Netherlands who saved significantly less penalties: $7.44 \%, S D=13.61, p=.005$ ). The goalkeeper performance (success rate) in Champions and Europa League matches as a function of nationality and type of penalty kick (shootout vs. in-game) is shown in Figure 2.

\section{Combined Analyses Collapsed over all Penalties}

Across all four tournaments, 629 different goalkeepers faced a total of 2,379 penalty kicks. On average, the goalkeeper success rate was 22.25 percent $(S D=29.89 ; 16.83$ percent for saved penalties; $S D=$ 27.46). A univariate ANOVA revealed neither a main effect for the factor nationality on the goalkeeper success rates $\left(F[8,620]=0.651, p=.734, \eta^{2}=0.008\right)$ nor on the percentages saved $(F[8,620]=0.878, p=$ $\left..535, \eta^{2}=0.011\right)$. Although the effect was non-significant, it can be considered a small effect for the percentage of saved penalties by statistical convention. None of the Bonferroni corrected pairwise comparisons revealed significant differences between any of the analyzed nations (all $p>.99$ ). Hence, there were no significant differences between the success rates of goalkeepers from different nations. A Kruskal-Wallis test for the nine different nation categories confirmed this non-significant effect on goalkeeper success rates $(\mathrm{X} 2=9.380, \mathrm{df}=8, p=.311)$ and on percentages saved $(\mathrm{X} 2=13.240, \mathrm{df}=8, p=$ 
.104). None of the nations significantly (all $p>.143$, two-tailed) differed from the overall sample mean success rate of 22.25 percent (except for the Netherlands: $12.98 \%, S D=14.91, p=.017$ ) nor from the 16.83 percent saved penalties (all $p>.261$; except for the Netherlands who saved significantly less penalties: $6.39 \%, S D=13.61, p=.001$ ). The goalkeeper performance (success rate) in penalty kicks faced during World Cups and European Championships as well as during Champions and Europa League matches as a function of nationality is shown in Figure 3.

\section{General Discussion}

The aim of the present research was to investigate if the nationality of goalkeepers has an influence on the success rates of saving penalty kicks. If this were the case and the data show that English goalies per se underperform in penalty kicks, the results would not only provide a possible explanation for England's poor performance in important penalty shootouts in the past but also potential evidence for the alleged 'goalkeeper problem'. However, the empirical data did not support either of these two stereotypes. Concerning our main research question, the success rate of English keepers was as high as the success rate of keepers from other nations. Linking the prevalence of lost penalty shootouts by the England men's national team to the nationality of the goalies would therefore be incorrect. Our results indicate that there are no significant differences between the success rates of goalkeepers from different nations (except for Dutch keepers, performing slightly worse than the population average), which, in turn, can be considered one counterargument against the stereotype that 'English goalies are no good' [7-10].

At a descriptive level of analysis, the average success rate of English goalkeepers in World Cups and European Championships is lower for in-game penalty kicks (16.67 \%) than for shootouts $(22.38 \%)$. In both cases, their average success rates are slightly below the respective total sample means for in-game penalties $(19.18 \%)$ and shootouts $(26.29 \%)$. In the Champions and Europa League, the average success rate of English goalies in shootouts $(14.29 \%$ ) is second to the lowest among the analyzed nations (total sample mean: $27.95 \%$ ) but it must be noted that only one English keeper participated in shootouts in the considered time periods (Paul Robinson lost with Tottenham Hotspur against PSV Eindhoven in the round of eight of the 2007/08 Europa League season). For in-game penalty kicks, on the other hand, England's goalkeepers have the highest average success rate (34.24\%) compared to the other nations considered in the analysis and is far above the total sample mean of $23.47 \%$. When taking all penalty kicks into account (shootouts and in-game during all four tournaments), the average success rate of English goalies $(28.45 \%$ ) is second to the highest (right behind Spain with an average success rate of $28.75 \%$ ) and, therefore, fairly above the total sample mean success rate of $22.25 \%$. Either way, none of these comparisons reached statistical significance, except that Dutch keepers performed significantly worse than keepers from the other nations. Considering these findings, we suggest that the factor nationality hardly explains meaningful variance in goalkeeper success rates in penalty kicks and that the reasons for the poor performance in penalty shootouts of the England national team in the past, as well as the quite negative public perception of their performance, most probably lie with other factors - including the unreliable measurement of penalty performance [15] and the public's general tendency of stereotyping [16] in everyday life and in the context of sports $[17,18]$. 
When taking a closer look at the descriptive results of the Champions- and Europa League, however, English goalkeepers stand out in a different aspect: With only twelve keepers, England has the smallest number of goalies who faced penalty kicks among the analyzed nations in the considered time periods. This raises the question if teams with English goalies simply commit less called fouls in the penalty box or if there are less English goalies playing for clubs who participate in the Champions and Europa League in general. The latter would mean that the very best clubs in European football prefer playing keepers from other nations over keepers from England. This seems to be tentatively supported by the fact that only 15 different English goalkeepers started for the teams in the Champions League between 2000/01 and 2019/20. From the seven other analyzed nations, only Argentina had less (ten goalkeepers) in this time period. In addition, the English goalies only played an average of 8.00 matches (again lowest of the seven analyzed nations), meaning that their clubs either got knocked out of the tournament relatively early or that they switched to keepers from different nations for most of their games. In contrast, Spain (37 starting goalies with an average of 19.35 matches played) and Germany (31 starting goalies with an average of 19.81 matches played) could be considered the nations with the most desirable goalkeepers based on their playing time in the Champions League within the last 20 years. However, when taking the average number of goals scored against keepers from the different nations per match as a proxy for performance, English goalkeepers again did not perform worse (1.43 goals/game) than Spanish (1.20 goals/game), German (1.45 goals/game), Italian (1.49 goals/game), French (1.42 goals/game), Brazilian (1.17 goals/game), Dutch (1.83 goals/game) or Argentinian goalkeepers (1.29 goals/game).

Investigating the reasons behind the lack of English goalies in the Champions League goes beyond the scope of the present study. However, the results of our study indicate that the nationality of a goalkeeper per se does not have an influence on their success rate in penalties and that English keepers presumably are not responsible for England's poor performance in penalty shootouts in the past. Considering this result, we provide a counterargument against the prevalent stereotype that 'English goalkeepers are no good'. In order to hold evidence-based results against the negative public opinion regarding English goalkeeping, future research should investigate other possible reasons behind the alleged 'goalkeeper problem' - the performance of English goalkeepers in penalty kicks is at least not an aspect that should contribute to this stereotype.

\section{Declarations}

\section{Availability of materials and data}

The datasets generated and analyzed during the current study are available from the corresponding author upon reasonable request.

\section{Acknowledgements}

Special thanks go to Kristen Clarke for proofreading the manuscript.

\section{Author Contributions}


M.B. and P.F. developed the study concept. Data collection was performed by M.B. The data analysis was performed by P.F. All authors contributed to the interpretation of the results. M.B. and P.F. drafted the manuscript, D.M. provided critical revisions. All authors approved the final version of the manuscript for submission.

\section{Declaration of Conflicting Interests}

The authors declared that they had no conflicts of interest with respect to their authorship or the publication of this article.

\section{References}

1. McFadden, B. R. Examining the gap between science and public opinion about genetically modified food and global warming. PloS One. 11(11), e0166140 (2016).

2. Steele, C. M. \& Aronson, J. Stereotype threat and the intellectual test performance of African Americans. Pers. Soc. Psychol. 69(5), 797 (1995).

3. Furley, P. \& Dicks, M. "White men can't jump." But can they throw? Social perception in European basketball. J. Med. Sci Spor. 24(5), 857-867 (2014).

4. Brinkschulte, M., Furley, P. \& Memmert, D. English Football Players are not as Bad at Kicking Penalties as Commonly Assumed. Rep. 10(1), 1-5 (2020).

5. Lyttleton, B. Twelve Yards: The Art and Psychology of the Perfect Penalty Kick (Penguin, 2015).

6. Which National Team has the Best Goalkeepers at the Moment? SportSkeeda (2020). Available at: https://www.sportskeeda.com/football/which-nation-best-goalkeepers (Accessed: 29th March 2021)

7. Are England Actually Bad at Taking Penalties - Or are the Goalkeepers to Blame? Eurosport (2018). Available at: https://www.theguardian.com/football/2007/aug/25/ newsstory.sport16 (Accessed: 29th March 2021)

8. England's No.1 Problem has Happened Again - The Poison Chalice of Being Three Lions' Goalkeeper. Mirror (2018). Available at: https://www.mirror.co.uk/sport/ football/news/englands-no1-problemhappened-again-11770653 (Accessed: 29th March 2021)

9. The Guardian. What is Wrong with England's Goalkeepers? The Guardian (2007). Available at: https://www.theguardian.com/football/2007/aug/25/newsstory.sport16 (Accessed: 29th March 2021)

10. The Guardian. The Secret Footballer: Why is England Lacking in Top Goalkeepers? The Guardian (2011). Available at: https://www.theguardian.com/football/blog/2011/sep/02/ secret-footballerengland-goalkeepers (Accessed: 29th March 2021)

11. Beilock, S. L., Jellison, W. A., Rydell, R. J., McConnell, A. R. \& Carr, T. H. On the causal mechanisms of stereotype threat: Can skills that don't rely heavily on working memory still be threatened? Soc. Psychol. B. 32, 1059-1071 (2006). 
12. Stone, J., Lynch, C. I., Sjomeling, M. \& Darley, J. M. Stereotype threat effects on black and white athletic performance. Pers. Soc. Psychol. 77(6), 1213-1227 (1999).

13. Heidrich, C. \& Chiviacowsky, S. Stereotype threat affects the learning of sport motor skills. Sport Exerc. 18, $42-46$ (2015).

14. Beilock, S. L. \& McConnell, A. R. Stereotype threat and sport: Can athletic performance be threatened? Sport Exerc. Psychol. 26, 597-609 (2004).

15. Schweizer, G., Furley, P., Rost, N. \& Barth, K. (2020). Reliable measurement in sport psychology: The case of performance outcome measures. Sport Exerc. 48, doi:10.1016/j.psychsport.2020.101663 (2020).

16. Fiske, S. T. \& Taylor, S. E. Social cognition (Reading, MA: Addison-Wesley, 1991).

17. Buffington, D. \& Fraley, T. Racetalk and sport: The color consciousness of contemporary discourse on basketball. Inq. 81, 333-352 (2011).

18. Stone, J., Perry, Z. W. \& Darley, J. M. "White men can't jump": Evidence for the perceptual confirmation of racial stereotypes following a basketball game. Basic Appl. Soc. Psych. 19, 291-306 (1997).

\section{Figures}

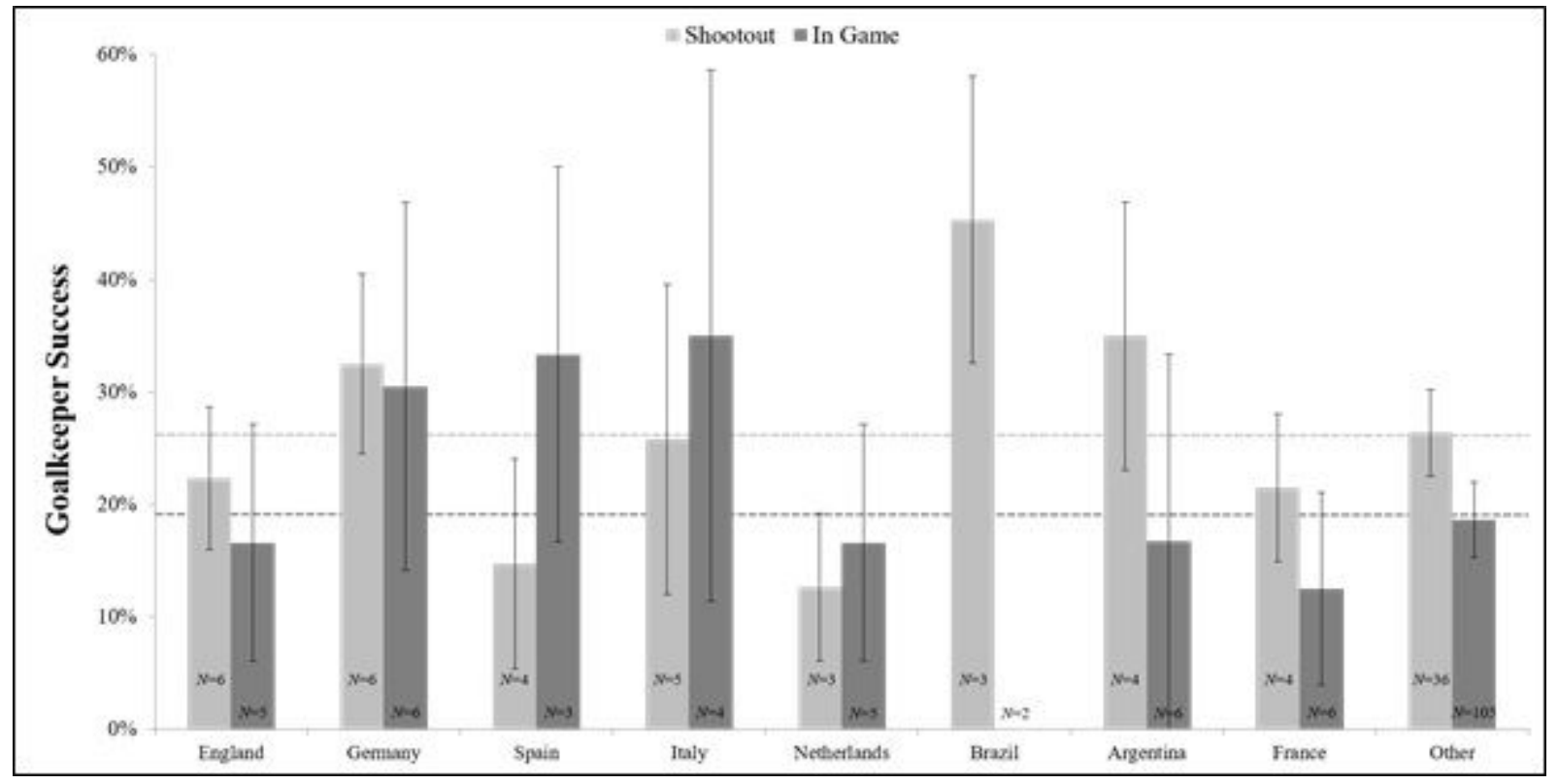

\section{Figure 1}

Mean percentages of the goalkeeper success ratios for penalty kicks faced during World Cup and European Championship matches as a function of goalkeeper nationality and type of penalty kick. The N's refer to the number of goalkeepers analyzed for each nation (171 of 710 penalty kicks were missed against 165 different goalkeepers in the analyzed time period). Error bars represent standard errors of the mean. 


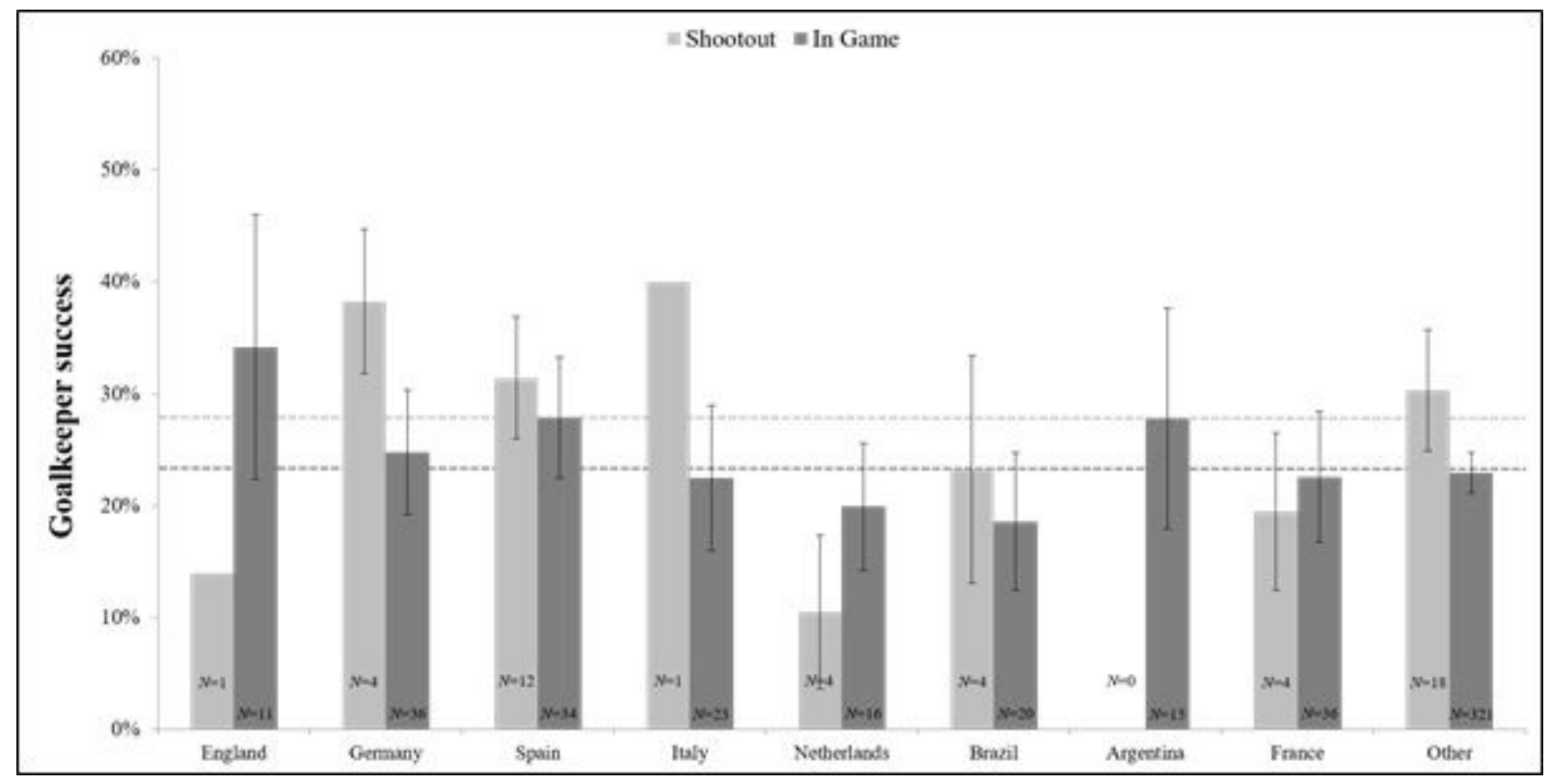

\section{Figure 2}

Mean percentages of the goalkeeper success ratios for penalty kicks faced during Champions League and Europa League matches as a function of goalkeeper nationality and type of penalty kick. The N's refer to the number of goalkeepers analyzed for each nation (426 of 1,669 penalty kicks were missed against 515 different goalkeepers in the analyzed time periods). Error bars represent standard errors of the mean.

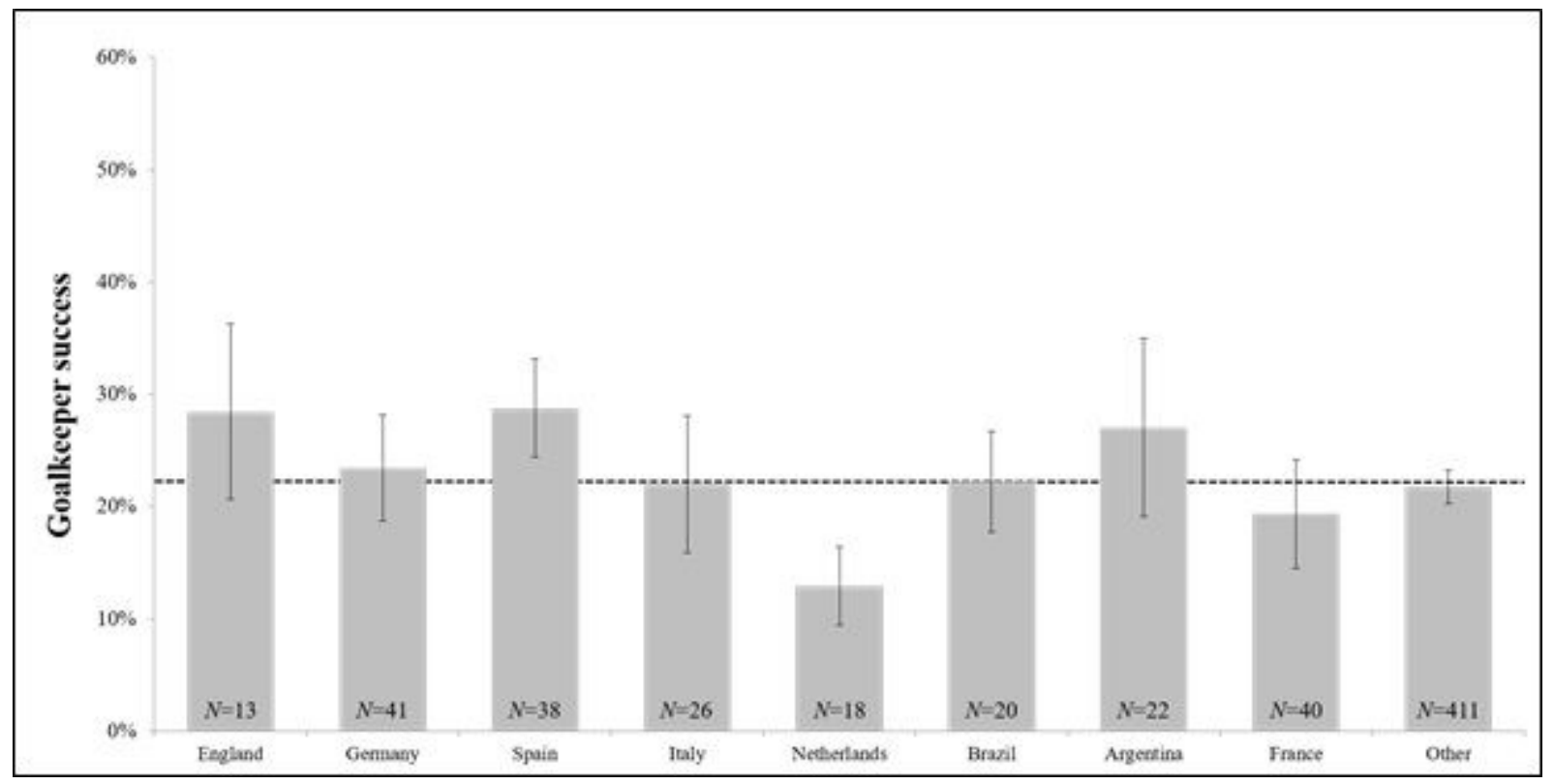

\section{Figure 3}

Mean percentages of the goalkeeper success ratios for penalty kicks faced (shootouts and in-game) during World Cup, European Championship, Champions League and Europa League matches as a function of goalkeeper nationality. The N's refer to the number of goalkeepers analyzed for each nation 
(597 of 2,379 penalty kicks were missed against 629 different goalkeepers in the analyzed time periods). Error bars represent standard errors of the mean. 